\title{
Frequency of number of roots and root canals of maxillary first premolar teeth.
}

\footnotetext{
1. BDS, M.Phil

Assistant Professor Oral Biology

Peshawar Dental College, Peshawa

2. BDS, M.Phil

Assistant Professor Oral Biology

Peshawar Dental College, Peshawar

3. BDS,

FCPS (Oral \& Maxillofacial Surgery)

Professor Oral \& Maxillofacial

Surgery

Peshawar Dental College, Peshawar.
}

Correspondence Address:

Dr. Munawar Aziz Khattak

Department of Oral Biology

Peshawar Dental College, Peshawar.

mak_kcd@hotmail.com

Article received on:

22/12/2020

Accepted for publication:

20/02/2021

\section{Munawar Aziz Khattak1, Sana Arbab², Syed Amjad Shah ${ }^{3}$}

ABSTRACT... Objective: To determine the frequency of the number of roots and root canals in a sample of 250 extracted maxillary first premolar teeth of patients visiting Peshawar Dental College and Hospital Khyber Pakhtunkhwa. Study Design: Cross Sectional. Setting: Department of Oral Biology, Peshawar Dental College and Hospital Khyber Pakhtunkhwa. Period: April 2016 to December 2016. Material \& Methods: A total of 250 extracted human maxillary first premolars were collected from the Department of Oral \& Maxillofacial Surgery, Peshawar Dental College, and Hospital Khyber Pakhtunkhwa. All teeth were visually inspected to count the number of roots. Subsequently, the access cavity was prepared, and pulp extirpated from each tooth. Endodontic explorer was used to locate the canal orifice(s) at the pulp chamber floor. Later the root canal orifices were injected with India ink to stain the canals. After that roots of teeth were sectioned at different levels to note down the number of canals. Data were analyzed using SPSS version 19. The statistical significance of the variations from mean values was considered significant if the p-value was less than 0.05. Results: Out of 250 maxillary first premolar teeth, $44.8 \%$ had one root, $40.4 \%$ had two separate and $12.8 \%$ had two fused roots. Three roots were seen in $2.0 \%$ teeth. Two root canals were present in the vast majority $(70.4 \%)$, whereas one and three root canals were seen in $27.6 \%$ and $2.0 \%$ teeth, respectively. The correlation between the number of roots and root canals of maxillary first premolar teeth was highly significant. Conclusions: There was a high frequency of maxillary first premolars with two roots and two root canals.

Key words: Maxillary First Premolar, Number of Root Canals, Root Form, Root Number, Root Sectioning, Tooth Morphology.

Article Citation: Khattak MA, Arbab S, Shah SA. Frequency of number of roots and root canals of maxillary first premolar teeth. Professional Med J 2021; 28(10):1513-1518. https://doi.org/10.29309/TPMJ/2021.28.10.6290

\section{INTRODUCTION}

Many patients who visit dental hospitals are suffering from toothache due to irreversible pulpitis and numerous other causes. ${ }^{1}$ The treatment of choice for irreversible pulpitis in the majority of these cases is the root canal treatment (RCT) of that tooth to alleviate pain. ${ }^{2,3}$ Root canal treatment is a discursive dental procedure and may lead to treatment failure if a dentist does not know the exact number of canals in a particular tooth. ${ }^{4}$ The internal anatomy of the root canal varies among individuals, depending on their genetic makeup and thus affecting the human races. ${ }^{5}$ Root canal anatomy is not as simple as the anatomy of the external root surface and should not be misguided by the simplicity and uniformity of the anatomy of the outer surface of the root. ${ }^{6}$ Knowledge of the root canal system of maxillary first premolars is essential during endodontic treatment to avoid complications and procedural errors that arise due to improper and conventional diagnosis, therefore, the failure or success of root canal treatment greatly depends upon the knowledge of tooth morphology. ${ }^{7}$

Maxillary first premolar (MFP) shows a wide variation regarding its external root morphology as well as its internal canal numbers. ${ }^{8}$ The external root form of maxillary first premolar comprises of a single, bifurcated, laminated, or three roots, of which the bifurcated root form is the most common. ${ }^{9}$ Single rooted maxillary first premolar is easy to extract as compared to two and three rooted forms. Likewise, it is easy to move a singlerooted tooth during orthodontic treatment than the two or three rooted tooth form..$^{10}$ The number 
of root canals in single, bifurcated, laminated, and three rooted maxillary first premolars vary from person to person depending upon their ethnicity. ${ }^{11}$ Özcan ${ }^{12}$ observed the incidence of single root varied from $15.5 \%$ to $55.8 \%$, two roots from $41.7 \%$ to $80.9 \%$, and three rooted from $0.0 \%$ to $9.2 \%$ in maxillary first premolars. Similarly, the percentage of single, two and three root canals ranged from $2.1 \%$ to $26.2 \%, 73.3 \%$ to $97.0 \%$ and $0.0 \%$ to $9.2 \%$ respectively. ${ }^{12}$

Several studies have been carried out ex vivo on root and canal morphology of maxillary first premolars in various populations using different methodologies like radiographic assessment, ${ }^{8}$ tooth decalcification and canal staining ${ }^{9}$, tooth sectioning ${ }^{12}$, or cone-beam computed tomography (CBCT). ${ }^{13}$ Neelakantan ${ }^{14}$ reported that canal staining and clearing techniques are easy to carry out and are as accurate as CBCT to study root canal systems.

The aim of the study is to determine the frequency of the number of roots and root canals of maxillary first premolar teeth in a sample population of patients visiting the Peshawar Dental College and Hospital, Khyber Pakhtunkhwa.

The results obtained from this study will be helpful in establishing a baseline data about the root canal system of maxillary first premolars. Also, this information will help the clinicians in the preparation of specific guidelines for endodontic treatment of these teeth which will improve the root canal therapy and hence will provide a good value of life to the general public.

\section{MATERIAL \& METHODS}

This in-vitro cross-sectional study was conducted at the department of Oral Biology, Peshawar Dental College and Hospital, from April 2016 to December 2016. A total sample of 250 extracted maxillary first premolars were collected via nonprobability convenience type sampling from patients treated at the hospital. Ethical Review Committee of Peshawar Medical and Dental College approved the study. Informed consent was taken from the patient or the patient's attendant before collecting the teeth for research purpose.

\section{Inclusion Criteria}

The extracted maxillary first premolar teeth with intact crown and root morphology having fully developed root apices were included in the study.

\section{Exclusion Criteria}

The extracted maxillary first premolar teeth with carious lesions, restorations, fractures, root resorptions or periapical pathologies were excluded from the study.

The teeth were washed gently with tap water after extraction to remove any blood or food debris. If dental calculus or soft tissue remnant being adhered to any tooth, it was removed by an ultrasonic scalar (Piezoelectric system, NSK Japan). The teeth were then placed in small labeled plastic bottles that contained $10 \%$ formalin to preserve them till the completion of the whole sample size and further processing.

All the teeth had undergone visual examination to count the number of roots in each tooth. On this basis, the maxillary first premolars had been divided into the following four groups ${ }^{8}$, as shown in Figure-1.

$\begin{array}{ll}\text { Group I: } & \text { Single root } \\ \text { Group II: } & \text { Two separate roots } \\ \text { Group III: } & \text { Two fused roots } \\ \text { Group IV: } & \text { Three roots }\end{array}$

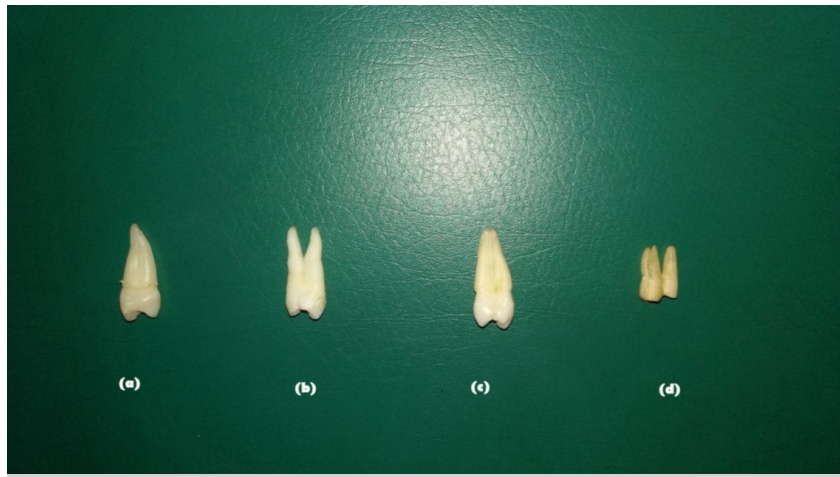

Figure-1. Grouping of MFP on the basis of number of roots.

Single (I), Two separate (II), Two fused (III), Three roots (IV) 
After visual examination, endodontic access cavities were prepared in all the teeth by using a high speed air turbine handpiece (PANA-MAX Japan Model PAX-SU B2) with diamond burs (BR-46 and TF-13 MANI Co. Japan). These teeth were then placed in $5.25 \%$ sodium hypochlorite solution (Haq Chemicals Pakistan) for 12 hours to dissolve the pulp tissue. Subsequently, canal orifice(s) were located and counted on the floor of the pulp chamber with endodontic explorer (Sybron endo DG-9). After that India ink (Jacksons Co., UK) was injected into the orifice(s) with the help of a disposable syringe (AMD $1 \mathrm{~mL} 27 \mathrm{G} * 1 / 2$ " Changzhou Co. China). The ink penetrated the canal and leaked out from the apical foramen. The teeth were then allowed to dry so that the canal outline gets stained. ${ }^{15}$ The dried teeth were cross-sectioned using a diamond blade mounted on a low speed saw (TechCut4 ${ }^{\mathrm{TM}}$ Allied High Tech Products. iNC-USA) at three levels of the root that is coronal one third, middle one third and apical one third. ${ }^{16}$ The images of these sectioned root parts were taken through Digital Camera (PL100, Samsung, Suwon, South Korea) and evaluated on a computer screen at a magnification of 40 times than normal to count the number of root canals. Two canals will be considered if they are present at two levels or more ${ }^{15}$, as shown in Figure-2.

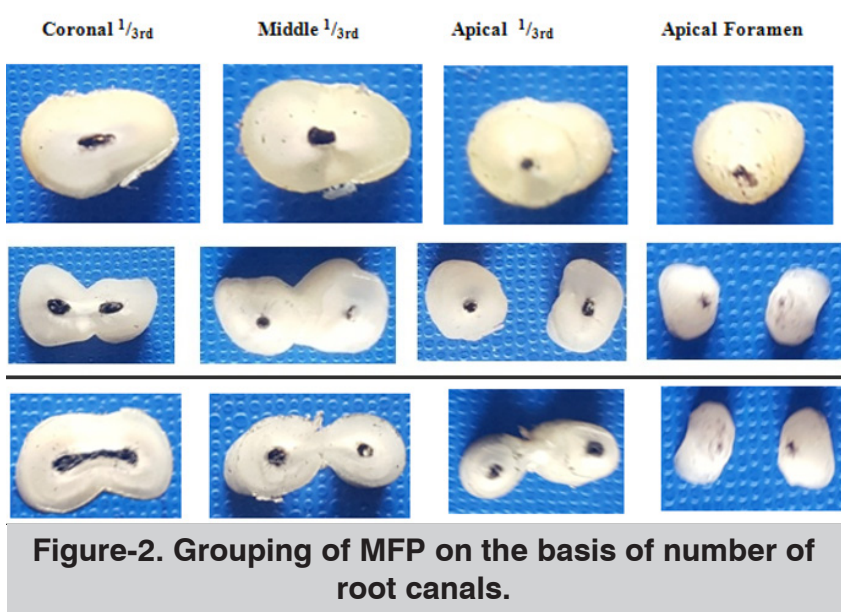

The data of examined teeth were recorded and evaluated to determine the frequencies and percentages of the number of roots and root canals of maxillary first premolars. The statistical analyses were performed using SPSS software (version 19). A relationship between the number of roots and root canals was demonstrated using the Pearson Chi-Square test. Variations, if any, from the mean values were considered statistically significant when the $p$-value was $<0.05$.

\section{RESULTS}

A total of 250 extracted human maxillary first premolars were assessed for the presence of the number of roots and root canals. The frequency distribution of these teeth according to the number of the roots and root canals were observed.

One hundred and twelve MFPs (44.8\%) had a single root compared to 101 (40.4\%) having two separate (including bifid root type) and 32 (12.8\%) had two fused roots. Five $(2.0 \%)$ premolars had three roots Table-I.

\begin{tabular}{|l|c|c|}
\hline Number of Roots & $\begin{array}{c}\text { Number of } \\
\text { Teeth }(\mathbf{n})\end{array}$ & $\begin{array}{c}\text { Percentage } \\
\text { (\%) }\end{array}$ \\
\hline Single root & 112 & 44.8 \\
\hline Two separate roots & 101 & 40.4 \\
\hline Two fused roots & 32 & 12.8 \\
\hline Three roots & 5 & 2.0 \\
\hline Total & 250 & 100.0 \\
\hline
\end{tabular}

Table-I. Frequency distribution of the maxillary first premolar teeth on the basis of the number of roots.

One hundred and seventy-six MFPs (70.4\%) had two root canals, followed by one canal found in $69(27.6 \%)$ MFPs. Three canals were present in only $5(2.0 \%)$ teeth Table-II.

\begin{tabular}{|l|c|c|}
\hline $\begin{array}{c}\text { Number of Root } \\
\text { Canals }\end{array}$ & $\begin{array}{c}\text { Number of } \\
\text { Teeth (n) }\end{array}$ & Percentage (\%) \\
\hline One & 69 & 27.6 \\
\hline Two & 176 & 70.4 \\
\hline Three & 5 & 2.0 \\
\hline Total & 250 & 100.0 \\
\hline $\begin{array}{c}\text { Table-II. Frequency distribution of the maxillary first } \\
\text { premolar teeth on the basis of the number of root } \\
\text { canals. }\end{array}$ \\
\hline \multicolumn{2}{|c|}{} \\
\hline
\end{tabular}

Single rooted teeth having one root canal were $58.0 \%$ and those having two root canals were $42.0 \%$. The maxillary first premolars with two separate roots had two root canals $(100.0 \%)$ only, one in each root. Two fused roots occasionally had a single canal (12.5\%) but predominantly 
had double canals (87.5\%) in their root canal system. Three rooted bicuspids specifically had three canals $(100.0 \%)$, one in each root arising from the pulp chamber floor and continued as three separate apical foramina. The " $p$ " value of 0.000 , as calculated by the Pearson Chi-Square test, showed a statistically significant difference between the number of roots and root canals of maxillary first premolars when compared with each other Table-III.

\begin{tabular}{|l|c|c|c|c|}
\hline \multicolumn{1}{|c|}{$\begin{array}{l}\text { Number of } \\
\text { Roots }\end{array}$} & \multicolumn{2}{|c|}{ Number of teeth "n" (\%) } & Total \\
\cline { 2 - 5 } & $\begin{array}{c}\text { One } \\
\text { RC }\end{array}$ & Two RC & $\begin{array}{c}\text { Three } \\
\text { RC }\end{array}$ & \\
\hline Single root & $\begin{array}{c}\mathrm{n}=65 \\
(58.0)\end{array}$ & $\begin{array}{c}\mathrm{n}=47 \\
(42.0)\end{array}$ & 0 & $\begin{array}{c}\mathrm{n}=112 \\
(44.8)\end{array}$ \\
\hline $\begin{array}{l}\text { Two separate } \\
\text { roots }\end{array}$ & 0 & $\begin{array}{c}\mathrm{n}=101 \\
(100.0)\end{array}$ & 0 & $\begin{array}{c}\mathrm{n}=101 \\
(40.4)\end{array}$ \\
\hline Two fused & $\mathrm{n}=4$ & $\mathrm{n}=28$ & 0 & $\begin{array}{c}\mathrm{n}=32 \\
(12.8)\end{array}$ \\
\hline roots & $(12.5)$ & $(87.5)$ & $\mathrm{n}=5$ & $\mathrm{n}=5$ \\
\hline Three roots & 0 & 0 & $(100.0)$ & $(2.0)$ \\
\hline Total & $\mathrm{n}=69$ & $\mathrm{n}=176$ & $\begin{array}{c}\mathrm{n}=5 \\
(2.0)\end{array}$ & $\begin{array}{c}\mathrm{n}=250 \\
(100.0)\end{array}$ \\
\hline
\end{tabular}

Table-III. Relation between the number of roots and root canals of maxillary first premolar teeth.

"P" value $=0.000$

$\mathrm{df}=6$ as calculated by Pearson Chi Square Test.

* Statistically significant difference $(p=0.000)$ between number of roots and root canals of maxillary first premolars $\mathrm{RC}=\quad$ Root canal

\section{DISCUSSION}

This study was conducted to determine the frequency of number of roots and root canals in extracted maxillary first premolar teeth of patients visiting Peshawar Dental College and Hospital, Khyber Pakhtunkhwa. In our study, $44.8 \%$ maxillary first premolars demonstrated a single root which was certainly lower than the finding (53.6\%) of Gupta et al. ${ }^{17}$, but higher than the frequency of single-rooted premolars seen in the Saudi (17\%) and Jordanian (30.8\%) population, respectively. ${ }^{8,15}$ The incidence of $44.8 \%$ singlerooted premolars supports the results of Ozcan ${ }^{12}$ who showed that the Turkish people had a frequency of $45.2 \%$ one rooted premolars. In our study (Table-I) and two other types of research as well ${ }^{8,12}$, premolars with two separate (40.4\%) and two fused (12.8\%) roots were considered as having two roots. This frequency (53.2\%) was higher than the prevalence of two roots (46.0\%) shown by Gupta ${ }^{17}$ and certainly lesser than the investigations conducted in Saudi (80.9\%), Jordanian (68.4\%) and Polish (75.4\%) people, respectively. ${ }^{8,15,18}$ Özcan ${ }^{12}$ found $55.7 \%$ two rooted maxillary first premolars in the Turkish population which was following the finding $(53.2 \%)$ of our work. In our study (Table-I), five (2.0\%) upper first bicuspids out of 250 total sample had three roots. Two $(0.8 \%)$ premolars out of these five had three separate roots i.e two buccal and one palatal. The other two (0.8\%) teeth showed two fused buccal roots and a separate palatal root whereas the remaining one $(0.4 \%)$ displayed bifurcation (separation) of two buccal roots at the apical one third and an independent palatal root. This frequency was considerably higher than that found in North Indian (0.4\%), Turkish (1.1\%), and Saudi $(1.2 \%)$ population as previously reported ${ }^{17,12,8}$ but lower than the prevalence $(9.2 \%)$ in Polish teeth. ${ }^{18}$ The disparity in results concerning the number of roots (single/two/three) of maxillary first premolars was often attributed to differences in sample size, the procedure to classify teeth, and ethnic backgrounds.

In our work (Table-II), a single root canal was present in $27.6 \%$ teeth. This percentage was considerably higher than the studies carried out in Saudi (8.9\%), Turkish (7.8\%), Chinese (14\%) and Polish (2.1\%) people respectively ${ }^{8,12,13,18}$, but lower than the results (48.8\%) of an earlier study..$^{19}$ The incidence of one canal (25.1\%) in Abella ${ }^{20}$ work was following our result. In the present study (Table-II), two canals had been found in $70.4 \%$ upper first premolars. This occurrence was much lower than those of earlier studies ${ }^{8,12,18}$, but higher than few reported in the literature. ${ }^{19,21}$ The finding (72.3\%) of Abella ${ }^{20}$ was coinciding with our result (70.4\%). The maxillary first premolars with three root canals ranged from $0.5 \%$ in one study ${ }^{22}$, to $9.2 \%$ in another study. ${ }^{18}$ In our study (Table-II), $2.0 \%$ teeth had three canals, all of them were 
found separately in each of the three roots. The differences, related to the number of root canals (one/two/three) of maxillary first premolars were usually enlightened as differences in population number, origin and evaluation techniques to identify root canals.

In our study, there was a highly significant difference $(p<0.05)$ when the number of roots of maxillary first premolar teeth was compared with their root canals (Table-III). It was noted in this study that the single-rooted teeth displayed greater variation in the number of root canals among the two and three rooted groups. This finding was supported by the result of one earlier study published in the literature. ${ }^{20}$

The results of this study showed that the maxillary first premolars had a great variation concerning the number of roots and root canals. The dental practitioners should always expect these anatomic deviations from the common form when dealing with these teeth and try to overcome them by using their knowledge and available tools.

\section{CONCLUSION}

It was concluded that the maxillary first premolars predominantly had one or two roots with two number of canals. The three rooted variants with three canals were rare.

Copyright@ 20 Feb, 2021.

\section{REFERENCES}

1. Timmerman A, Parashos P. Management of dental pain in primary care. Aust Prescr. 2020; 43(2):39-44.

2. Asgary S, Verma P, Nosrat A. Treatment outcomes of full pulpotomy as an alternative to tooth extraction in molars with hyperplastic/irreversible pulpitis: A case report. Iran Endod J. 2017; 12(2):261-65.

3. Gemmell A, Stone S, Edwards D. Investigating acute management of irreversible pulpitis: A survey of general dental practitioners in North East England. Br Dent J. 2020; 228(7):521-26.

4. Tabassum S, Khan FR. Failure of endodontic treatment: The usual suspects. Eur J Dent. 2016; 10(1):144-47.
5. Naseri M, Mozayeni MA, Safi Y, Heidarnia M, Baghban AA, Norouzi N. Root canal morphology of maxillary second molars according to age and gender in a selected Iranian population: A cone beam computed tomography evaluation. Iran Endod J. 2018; 13(3):37380.

6. Mohhsen AS, Razmi H, Sadegh M. Evaluation of anatomy and morphology of human mandibular premolar teeth by cone-beam computed tomography in Iranian population. J Dent Med. 2013; 26(3):203210.

7. Iqbal A. The factors responsible for endodontic treatment failure in the permanent dentition of the patients reported to the college of dentistry, the University of Aljouf, Kingdom of Saudi Arabia. J Clin Diagn Res. 2016; 10(5):146-48.

8. Atieh MA. Root and canal morphology of maxillary first premolars in a Saudi population. J Contemp Dent Pract. 2008; 9(1):46-53.

9. Senan EM, Alhadainy HA, Genaid TM, Madfa AA. Root form and canal morphology of maxillary first premolars of a Yemeni population. BMC Oral Health, 2018; 18(1):94-104.

10. Ruan MJ, Chen G, Xu TM. Comparison of orthodontic tooth movement between adolescents and adults based on implant superimposition. PLoS One. 2018; 13(5):e0197281.

11. Sulaiman AO, Dosumu OO, Amedari M. Maxillary first premolar with three root canals: A case report. Ann Ib Postgrad Med. 2013; 11(2):105-108.

12. Özcan E, Çolak H, Hamidi MM. Root and canal morphology of maxillary first premolars in a Turkish population. J Dent Sci. 2012; 7(4):390-4.

13. Tian YY, Guo B, Zhang R, Yu X, Wang H, Hu T, et.al. Root and canal morphology of maxillary first premolars in a Chinese subpopulation evaluated using cone beam computed tomography. Int Endod J. 2012; 45(11):9961003.

14. Neelakantan P, Subbarao C, Subbarao CV. Comparative evaluation of modified canal staining and clearing technique, cone-beam computed tomography, peripheral quantitative computed tomography, spiral computed tomography, and plain and contrast medium-enhanced digital radiography in studying root canal morphology. J Endod. 2010; 36(9):1547-51.

15. Awawdeh L, Abdullah $\mathrm{H}$, Al-Qudah A. Root form and canal morphology of Jordanian maxillary first premolars. Journal of Endodontics. 2008; 34(8):95661. 
16. Khedmat S, Assadian H, Saravani AA. Root canal morphology of the mandibular first premolars in an Iranian population using cross-sections and radiography. Journal of endodontics. 2010; 36(2):2147.

17. Gupta S, Sinha DJ, Gowhar O, Tyagi SP, Singh NN, Gupta S. Root and canal morphology of maxillary first premolar teeth in north Indian population using clearing technique: an in vitro study. Journal of Conservative Dentistry: JCD. 2015; 18(3):232.

18. Lipski M, Woźniak K, Łagocka R, Tomasik M. Root and canal morphology of the first human maxillary premolar. Durham Anthropol J. 2003; 12:2-3.
19. Deng D, Zhang M, Wu M. The morphology study of root canal system of permanent teeth. Sichuan J Anat. 2004; 12:22-6.

20. Abella F, Teixido LM, Patel S, Sosa F, Sindreu FD, Roig $\mathrm{M}$. Cone-beam computed tomography analysis of the root canal morphology of maxillary first and second premolars in a Spanish population. J Endod. 2015; $41(8): 1241-7$.

21. Różyło TK, Miazek M, Kalinowska IR, Burdan F. Morphology of root canals in adult premolar teeth. Folia Morphol. 2008; 67(4):280-85.

22. Pineda F, Kuttler Y. Mesiodistal and buccolingual roentgenographic investigation of 7,275 root canals. Oral Surg Oral Med Oral Pathol. 1972; 33(1):101-10.

\begin{tabular}{|c|c|c|c|}
\hline \multicolumn{4}{|c|}{ AUTHORSHIP AND CONTRIBUTION DECLARATION } \\
\hline Sr. \# & Author(s) Full Name & Contribution to the paper & Author(s) Signature \\
\hline 1 & $\begin{array}{l}\text { Munawar Aziz Khattak } \\
\text { Sana Arbab }\end{array}$ & $\begin{array}{l}\text { Conception and design, } \\
\text { Acquisition, Analysis and } \\
\text { interpretation of data, } \\
\text { Drafting the work. } \\
\text { Critical review of the work }\end{array}$ & $j\left(v^{\prime \prime}\right.$ \\
\hline 3 & Syed Amjad Shah & $\begin{array}{l}\text { Final approval of the version } \\
\text { to be published. }\end{array}$ & Aamiscers \\
\hline
\end{tabular}

